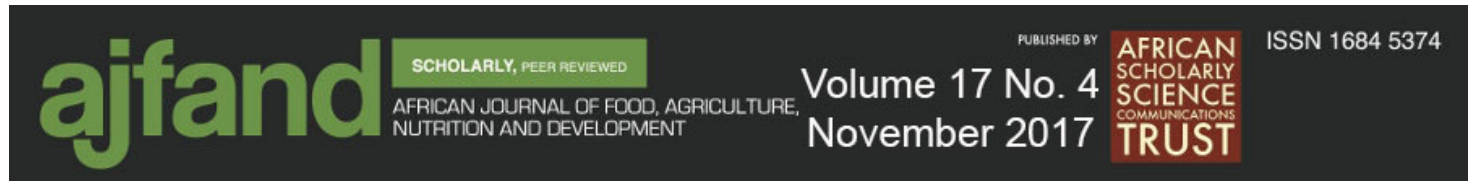

\title{
PREVALENCE OF IODINE DEFICIENCY AMONG SCHOOL CHILDREN AND ACCESS TO IODIZED SALT IN ZAMBIA
}

$$
\text { Katongo } C^{1 *} \text {, Kabaghe } C^{2} \text {, Mubanga } F^{2} \text { and W Siamusantu }{ }^{2}
$$

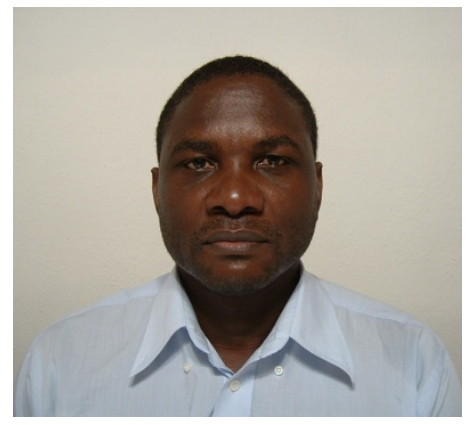

\section{Cyprian Katongo}

*Corresponding author's email: ckatongo@unza.zm

${ }^{1}$ University of Zambia, Department of Biological Sciences, P.O. Box 32379, Lusaka, Zambia

${ }^{2}$ National Food and Nutrition Commission Zambia, P.O. Box 32669, Lusaka, Zambia 


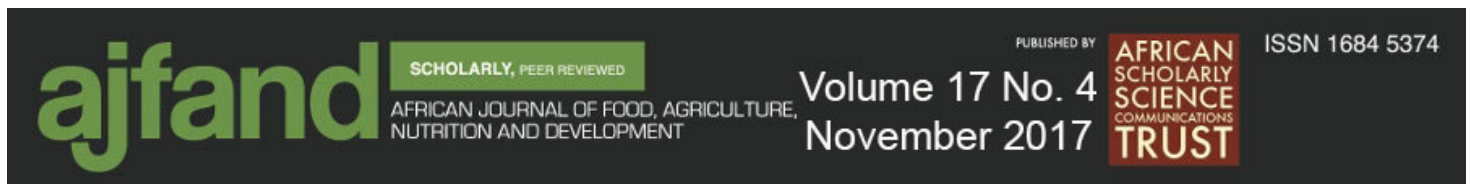

\begin{abstract}
This study, which covered all the ten provinces of Zambia, aimed at assessing the Iodine Deficiency prevalence, and access to adequately iodised salt in the country. It was carried out in 2011 and entailed determining the urinary iodine concentration (UIC) among 1, 283 school children from 30 selected schools and the amount of iodine in 875 salt samples collected from the households of the children. The iodine concentration was also determined in salt samples collected from 365 salt traders near the selected schools. Each of the salt traders was requested to complete a questionnaire. In addition, a questionnaire was administered to 75 teachers from the selected schools. The Urinary Iodine Concentration (UIC) was assayed by the Sandell-Kolthoff reaction, after digesting the urine with Ammonium Persulfate at $100^{\circ \mathrm{C}}$. The iodine concentration in the salt was determined using the quantitative titrimetric method. The data for the UIC and salt iodine plus data from questionnaires were analysed using Excel and Statistical Package for Social Sciences version 15 (SPSS 15). The median urinary iodine concentration (MUIC) was $248.5 \mu \mathrm{g} / 1$ and the Interquartile Range (IQR) was $145-380 \mu \mathrm{g} / \mathrm{L}$. These results indicated that Iodine Deficiency was not of public health concern among children in Zambia at the time of this study. However, the proportion of households with access to adequately iodised salt (15-40 ppm iodine) was $53 \%$, which is below the recommended target of $90 \%$ or more household coverage. Results from questionnaires indicated that the challenges faced by the Zambian Government in attaining Universal Salt Iodisation (USI) include: (i) lack of sustainability of local salt iodisation in local salt producing areas, (ii) weak enforcement of the law on salt iodisation, (iii) poor packaging and storage of salt by traders and households, (iv) limited knowledge of the link between lack of iodine in salt and iodine deficiency, and (v) relatively high cost of imported iodised salt in local salt producing areas.
\end{abstract}

Key words: Iodized, Salt, Iodine Deficiency, Universal Salt Iodisation, Zambia 


\section{INTRODUCTION}

Iodine is present in the body in trace amounts, mainly in the thyroid gland. Its main role is in the biosynthesis of thyroid hormones. When the body does not get enough iodine, thyroid hormone biosynthesis is impaired, resulting in hypothyroidism and many functional and developmental abnormalities collectively called "Iodine Deficiency Disorders (IDD)", which can affect the foetus, neonates, children and adolescents as well as adults. Goitre is the most visible manifestation of IDD [1-2]. However, the most damaging disorders induced by iodine deficiency (ID) are irreversible mental retardation and cretinism [3-5]. If ID occurs during the most critical period of brain development (from the foetal stage up to the third year after birth), the resulting thyroid failure will lead to irreversible alterations in brain function [6-8].

Women suffer from thyroid disorders more frequently than men of the same age [9]. During pregnancy, the mother's thyroid gland is subjected to increased demand for iodine because the foetus completely depends upon the mother for thyroid functions [10]. Therefore, severe maternal ID in early pregnancy may result in irreversible cretinism in children as well as miscarriages, stillbirths, and low-birth weight babies [11-12]. Even mild ID can have silent and invisible consequences, such as decreases in cognitive capacity and subtle psychomotor defects in neonates [13]. Because ID must be corrected before ovulation and conception occur [9], the iodine status of adolescent females should also be of concern.

Although some communities can get enough iodine from their natural foods, especially those who have access to sea food, most communities depend on iodised salt, which is one of the cheapest and most effective sources of dietary iodine. Universal Salt Iodisation (USI) strategy was adopted globally as an important strategy for the elimination of ID [14]. The USI was recommended by a joint World Health Organisation (WHO), United Nations Children's Fund (UNICEF) and the International Council for the Control of Iodine Deficiency Disorders (ICCIDD) expert committee; it is a policy of iodizing all salt used in households, catering, food processing, food industry and agriculture [14]. It is also aimed at ensuring that $90 \%$ or more households have access to adequately iodised salt [14].

The recommended methods of determining whether a given community is consuming adequate amount of iodine in the daily diet are by: (i) determination of the amount of iodine in the salt in their households and (ii), determination of the amount of iodine excreted in the urine. It is also important to monitor the iodine content in the salt at the point of manufacture, and at the retail stores [14]. The WHO criteria for assessing iodine nutrition based on median urinary iodine concentrations (MUIC) among school-age children are as follows: MUIC less than $20 \mu \mathrm{g} / \mathrm{L}$ means insufficient iodine intake that may lead to severe ID; MUIC of 20-49 $\mu \mathrm{g} / \mathrm{L}$ means insufficient iodine intake causing moderate ID; MUIC of 50-99 $\mu \mathrm{g} / \mathrm{L}$ means insufficient iodine intake causing mild ID; MUIC of 100-199 $\mu \mathrm{g} / \mathrm{L}$ means adequate iodine intake and optimal iodine nutritional status; MUIC of 200-299 $\mu \mathrm{g} / \mathrm{L}$ means more than adequate iodine intake causing risk of iodine induced hyperthyroidism (IIH); MUIC of $300 \mu \mathrm{g} / \mathrm{L}$ and above means excess iodine intake and risk of IIH and auto-immune thyroid disease [14]. The criteria for 
monitoring progress towards sustainable elimination of IDD at household level state that the iodine content in salt should not be less than $15 \mathrm{ppm}$, which indicates inadequate level of iodine [14]. Salt iodine content of $15-40 \mathrm{ppm}$ indicates adequate level of iodine; above $40 \mathrm{ppm}$ indicates excess amount of iodine content in the salt. The recommended WHO/UNICEF/ICCIDD criteria for assessing progress towards sustainable elimination of ID in a target population is that over $90 \%$ of households should have access to adequately iodised salt; less than $50 \%$ of school-age children should have UIC below $100 \mu \mathrm{g} / \mathrm{L}$ and less than $20 \%$ of school-age children should have UIC below $50 \mu \mathrm{g} / \mathrm{L}$ [14$16]$.

In 1993, Zambia conducted a baseline survey to assess the prevalence of IDD in line with the activities of WHO, UNICEF and ICCIDD who were concerned about IDD globally. Results of the baseline survey indicated that ID was of public concern in Zambia [17]. Following the baseline survey, the National Food and Nutrition Commission (NFNC) of Zambia and UNICEF supported enforcement of the USI Law and salt monitoring was intensified especially in border areas, but also at wholesale, retail, and household levels [18]. Several workshops were held to build the capacity of health care workers and law enforcement officers (Customs officers, Zambia Revenue Authority officers and Environmental Health Technicians (EHTs)) in salt monitoring. In Kasempa and Kaputa where there was significant local salt production, measures were taken to encourage iodisation of the locally produced salt. Support was given to the local communities in terms of iodisation machines and potassium iodate supplies [18]. Iodised oil capsules were procured and distributed to school children and pregnant women in Gwembe District after it was found to have severe IDD in 1995 [18]. A full time Micronutrient Programme Manager was appointed to oversee the implementation of, among other things, the IDD programme. The Programme Manager was to undertake periodic surveys to monitor and evaluate the efficacy of the IDD control programme. A focal point person was appointed by NFNC to oversee the IDD control programme. In addition, the 1978 Food and Drugs Act Cap 303 of the Laws of Zambia was amended in 1994 and 2000; making it mandatory for all salt intended for human consumption to be iodised. The Food and Drugs Control Laboratory was then strengthened, with the support of UNICEF, and was able to carry out urinary iodine determination and salt iodine analysis. Salt analysis was also being done at mini laboratories that were set up in five border districts [18].

The first ID national impact survey was conducted in 2002 to monitor the impact of the USI policy in Zambia [18]. This survey assessed the UIC in school children as a proxy for the iodine nutritional status of the Zambian population and proportion of households with salt containing $15-40 \mathrm{ppm}$ iodine as a proxy for access to adequately iodised salt [18]. The United Nations Children's Fund (UNICEF) supported the local iodisation of salt in Kasempa and Kaputa (local salt producing areas) and an assessment by Besa and Habulembe-Mugode [19] revealed that $84 \%$ of local salt producers in Kasempa iodised their salt while only $34 \%$ of the local producers in Kaputa iodised their salt.

The current study was the second Zambian ID impact survey, carried out in 2011. It used the same approach as the 2002 survey but also included administration of questionnaires on selected households, teachers and traders. 


\section{METHODS}

\section{Study design}

This was a cross-sectional two-stage national survey in which children from 30 primary schools (clusters) from various districts of Zambia were targeted. It also involved review of literature related to IDD and USI policy in Zambia, review of the baseline national ID survey and two ID impact surveys [14, 17-20] in addition to questionnaire administration.

\section{Ethical considerations}

Ethical clearance was obtained from the Biomedical Ethics Committee of the University of Zambia and permission to carry out each of the two ID impact surveys was given by the offices of the Permanent Secretaries in the Ministries of Health and Education before commencement of the study. Before collection of urine samples from school children, consent was obtained from the respective parent or guardian while assent was obtained from the participating child.

\section{Target groups}

Primary school children aged 7-12 years in Grades I to V were included for the purpose of collection of urine samples to be used for determination of MUIC while households of the participating children were included for the purpose of assessment of access, utilization and coverage of adequately iodised salt as well as awareness on IDD problems and iodised salt. Selected teachers from the schools were included to determine their level of knowledge of the importance of dietary iodine and of IDD. Selected salt traders were also included for the purpose of assessing their awareness about IDD problems and importance of iodised salt.

\section{Selection of schools}

A simple systematic method was used to select 30 schools from the 10 provinces based on the complete list of all registered Primary/Basic/Community schools in Zambia, made available by the Ministry of Education. The interval $(\mathrm{k})$ for selecting schools was calculated as the total number of schools in the country divided by the number of clusters. This was followed by the picking, at random, the first number from the table of random numbers [14].

\section{Selection of school children and households}

The number of children aged 7-12 years targeted for selection at each school for urine collection in the national survey was determined following the standard procedures [14, 16]. The actual sample size had an allowance of 5\% for non-compliance and ensured that the number satisfied the criteria that with $95 \%$ confidence, the results were valid if ID prevalence was $50 \%$ or less, with a relative precision of $5 \%$ [14]. Therefore, fifty children per school were targeted in this study. The children were randomly selected from within the target age group. Households included in the survey were those with the sampled school children. 


\section{Collection of urine samples}

Each index child provided approximately $10-20 \mathrm{ml}$ of spot urine collected in a sterile, iodine-free $40 \mathrm{ml}$ plastic universal urine container. Two aliquots were transferred from each urine sample into two sterile, iodine-free $5 \mathrm{ml}$ cryovials with tight fitting screw tops. Each cryovial was labelled with the child's serial number, date of collection, name of the school, the district and province. The labelled cryovials were then packed in two sets of racks and stored in a cooler box and transported to a holding place where they were stored in a refrigerator at $4^{\circ} \mathrm{C}$. One set of the urine samples was transported by courier to Tanzania Food and Nutrition Centre, Tanzania, for MUIC determination.

\section{Collection of salt samples}

From the household of each participating school child, a salt sample weighing 20 grams was collected wherever available. The salt sample collected from each participating household was then placed in a clean, iodine-free black polythene bag and labelled with the child's serial number, date of collection, the district and province; all the salt samples were kept in clean sacks away from light. The salt samples were transported to the Food and Drugs Control Laboratory in Lusaka for analysis.

\section{Administration of questionnaires}

Self-designed and pre-tested questionnaires were administered on the head of each participating household, on selected teachers and on selected salt traders to get information about salt handling, salt storage and their knowledge of the ID problem and iodised salt.

\section{Analysis of Urine Samples}

The Urinary Iodine Concentration (UIC) was assayed by Sandell-Kolthoff reaction (Method A), after digesting the urine with Ammonium Persulphate at $100^{\circ} \mathrm{C}[14-16,22]$. During the analysis, externally checked internal Quality Control (QC) solutions covering low, medium and high iodine concentration were used and run together with urine samples within and between assays. Validation of the results was also done on $10 \%$ of the total samples, randomly sampled and assessed for reproducibility by different people.

\section{Analysis of Salt Samples}

The procedure used for salt iodine determination was the quantitative titrimetric method for determining iodine from iodate in salt since the salt on the Zambian market is fortified with potassium iodate $\left(\mathrm{KIO}_{3}\right)$ [23].

\section{Analysis of data from questionnaires}

Data from questionnaires were entered into Epidata version 3.1 (Epi 3.1). The data were then exported to Excel and SPSS 15. Descriptive statistics were generated using frequency tables.

\section{Statistical analysis of data}

The results for the UIC and salt titration were separately entered into the Statistic Package for Social Sciences version 15 (SPSS 15) software. Descriptive statistics were then generated using frequency tables. 


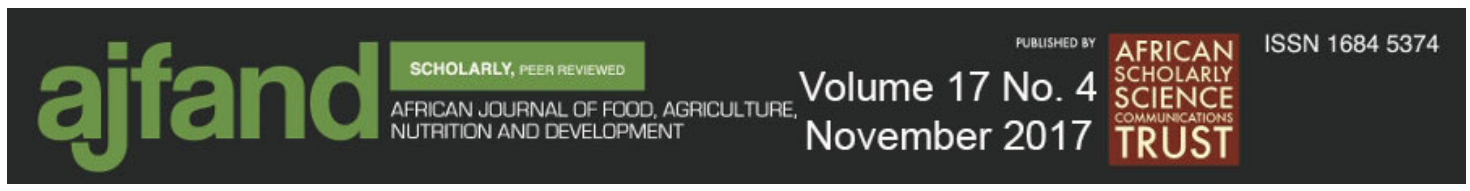

\section{RESULTS}

\section{Number of samples and questionnaires}

Data in Table 1 show the total number of urine and salt samples collected and the number (\%) analysed. Of the 1342 urine samples collected 59 (3.4\%) were not analysed because of loss during transportation. In addition, $27(3.0 \%)$ salt samples collected from the households were also not analysed because of loss during handling. All the questionnaires distributed were collected and analysed statistically.

\section{Median Urinary Iodine Concentration (MUIC)}

The MUIC obtained for all the children in the present study was $244.8 \mu \mathrm{g} / \mathrm{L}$ with interquartile range (IQR) of $145-380 \mu \mathrm{g} / \mathrm{L}$; this was very similar to the MUIC of $245.0 \mu \mathrm{g} / \mathrm{L}$ reported in the 2002 study. Characterization of the MUIC obtained for all the children in the present study (2011) is presented in Table 2, using the recommended WHO/UNICEF/ICCIDD format [14]. For comparative purposes, values for the 1993 baseline survey and 2002 impact survey are also shown in Table 2 . In the present study, the proportion of children with MUIC below $20 \mu \mathrm{g} / \mathrm{L}$ was $1.5 \%$, while the proportion with MUIC $100-199 \mu \mathrm{g} / \mathrm{L}$ was $24.9 \%$ and the proportion with MUIC above $299 \mu \mathrm{g} / \mathrm{L}$ was 39.4\%. Corresponding results for the 1993 and 2002 surveys are presented in Table 2.

Over the period 1993 to 2011, there has been a significant reduction in the proportion of school children with MUIC below $20 \mu \mathrm{g} / \mathrm{L}$; there was a reduction in proportion with MUIC 200-299 $\mu \mathrm{g} / \mathrm{L}$ and an increase in the proportion with MUIC above $299 \mu \mathrm{g} / \mathrm{L}$. Severe to mild iodine deficiency dropped from $72.0 \%$ in 1993 to $14.1 \%$ in 2011 , although the result for 2011 was higher than the $4.0 \%$ obtained in 2002 .

\section{Iodine concentration in salt samples}

Household salt iodine concentration values are presented in Table 3 [14]. The proportion of households with salt iodine concentration less than 15 ppm was $20.2 \%$, while the proportion with $15-40 \mathrm{ppm}$ was $53.3 \%$ and that with over $40 \mathrm{ppm}$ were $26.5 \%$ (Table 3 ). Results for the 2002 survey are also included. The trend in the coverage of iodised salt for Zambia over the years 2002 to 2011 shows a significant increase in the proportion of households with optimally iodised salt (15-40 ppm) and an increase in the proportion of households with inadequately iodised salt (less the $15 \mathrm{ppm}$ ). The trend also shows a reduction in the proportion of households with salt iodine concentration above the required level (above 40ppm).

\section{Sustainable indicators for elimination of Iodine Deficiency}

In the current study, the overall ID elimination indicators for Zambia are presented in Table 4 [14]. The indicators for 1993 and 2002 are also given in Table 4 for comparative purposes. The 2002 data show that adequate amount $(\geq 15 \mathrm{ppm})$ of iodine was available in $92.5 \%$ households, which is greater than the recommended $90 \%$.

\section{Results from Questionnaires}

Results from questionnaires administered on households indicated that only slightly less than $50 \%$ of respondents knew at least one type of IDD; far less than half of the households attributed lack of iodine in food to goitre, indicating lack of knowledge of 


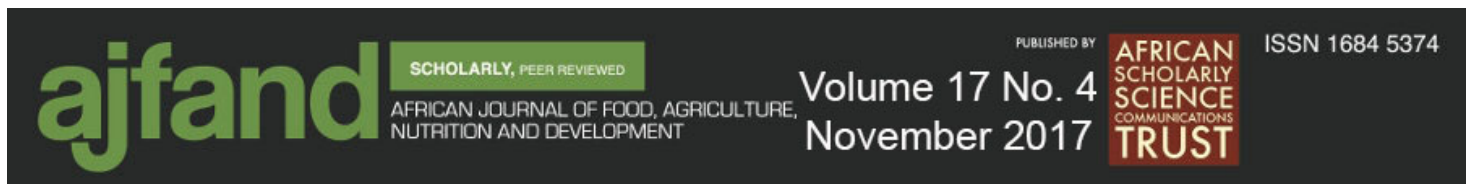

the link between iodised salt and iodine deficiency. Few respondents knew that mental retardation, cretinism and miscarriages were linked to lack of iodine [Table 5].

Most teachers (74.2\%) are aware that consumption of iodised salt prevents goitre. Fewer $(30.6 \%)$ are aware that adequate consumption of iodine helps improve school performance of vulnerable children and very few (4.8\%) are aware that it contributes to the prevention of mental retardation and miscarriages $(1.6 \%)$.

Results from traders' questionnaires indicated that most of the salt brands they stocked were imported from Botswana (42.9\%). Miscellaneous brands on the market accounted for $20.3 \%$ while unknown brands accounted for $36.8 \%$.

\section{DISCUSSION}

\section{Successes of implementing the USI policy in Zambia}

The 2002 and 2011 USI policy impact surveys revealed consistency in the MUIC among the Zambian pupils at $245.0 \mu \mathrm{g} / \mathrm{L}$ and $244.8 \mu \mathrm{g} / \mathrm{L}$, respectively. These values were above the recommended WHO/UNICEF/ICCIDD range of 100-199 $\mu \mathrm{g} / \mathrm{L}$ that indicates optimum status of iodine nutrition. The MUIC obtained in 2002 and 2011 indicated improvement from the results of the 1993 IDD baseline survey, in which the MUIC was $49.0 \mu \mathrm{g} / \mathrm{L}$. The USI impact survey results in 2002 indicated that ID was not of public health concern among school children in Zambia at the time of the study, although the MUIC was above the optimum range of $100-199 \mu \mathrm{g} / \mathrm{L}[20,24]$. A similar deduction can be made for the school children in the present study with MUIC of $244.8 \mu \mathrm{g} / \mathrm{L}$ [20].

The 2002 and 2011 USI policy impact surveys revealed that the proportion of households with access to adequately iodised salt (15-40 ppm) increased from $28.5 \%$ in 2002 to $53.3 \%$ in 2011 . Further analysis of the data shows that salt with iodine content $\geq 15.0 \mathrm{ppm}$ was available in $92.5 \%$ of households in 2002 compared to $79.8 \%$ of households in 2011. This indicated effective implementation of the USI strategy in 2002 compared to relaxation in the implementation in 2011. This may be due to lack of monitoring of implementation of the USI strategy.

\section{Some challenges facing effective implementation of the USI policy}

Data obtained in the present study seems to indicate that some of the gains made following the implementation of the USI policy in 1995 have since been weakened due to lack of sustainability. In addition, the authors' personal observation revealed that iodisation of locally produced salt in Kaputa and Kasempa Districts has since been discontinued.

Results of the USI impact surveys revealed that some proportion of the school children may be at risk of developing Iodine Induced Hyperthyroidism (IIH) with MUIC of 245.0 $\mu \mathrm{g} / \mathrm{L}$ in 2002 and $244.8 \mu \mathrm{g} / \mathrm{L}$ in 2011 . Results also revealed an increase in the proportion of school children with UIC less than $100 \mu \mathrm{g} / \mathrm{L}$ - from $4.0 \%$ in 2002 to $14.1 \%$ in 2011. These results suggest the need for some programmatic attention to improve on the implementation of the USI strategy in the country. 


\section{CONCLUSION}

Results of this study indicated that Zambia has made some gains in the implementation of the USI policy. The government should strengthen the monitoring of salt iodine content at the point of entry into Zambia, at wholesale, retail and household levels to ensure correct iodisation levels. There should be close liaison between foreign salt producers (who are mostly in Botswana) and the IDD programme in Zambia to ensure correct iodisation levels of salt.

From the results of this study, it is recommended that in order to effectively monitor the iodine nutrition status, there is need for Zambia to build in-country technical and financial capacity to regularly monitor the iodine content in the different brands of salt sold in the country. This should be carried out routinely every year. Similar monitoring should be carried out at the trade stores and the households. The UIC in school children should also be conducted regularly.

It is also recommended that a district IDD survey should be carried out in each of Kaputa and Kasempa parallel to the National IDD survey, since communities in Kaputa and Kasempa will continue to produce local salt.

Awareness of adequate nutrition especially with reference to micronutrients should be increased through school curriculum review and increased community sensitization. In addition, consumers and traders should be sensitized about the role of iodised salt in the prevention of IDDs so that the USI programme can be sustainable.

\section{ACKNOWLEDGEMENTS}

We would like to acknowledge the contributions and support of NFNC, Zambia; USAID, Zambia; UNICEF, Zambia; Ministry of Health, Zambia; Ministry of Education Science Vocational Training and Early Education, Zambia; Food and Drugs Control Laboratory, Zambia; Tropical Diseases Research Centre, Zambia; Government Laboratories, Harare, Zimbabwe and Tanzania Food and Nutrition Centre, Dar es Salaam, Tanzania. The Principal Investigator received training at the Nutritional Intervention Research Unit of the South African Medical Research Council, in Cape Town, with financial support from Nestlé Foundation of Switzerland. 


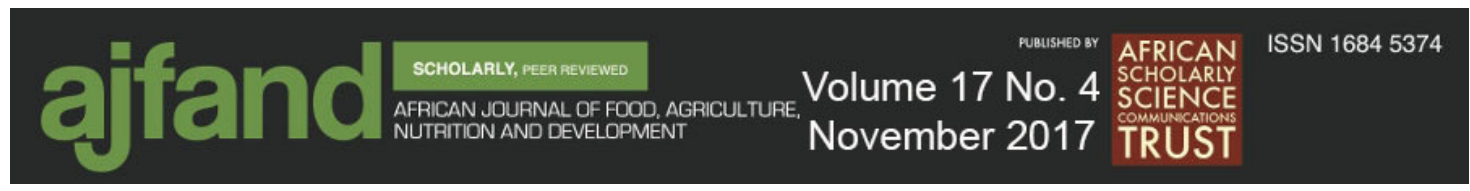

Table 1: Numbers (\%) of the samples and questionnaires used in the study

\begin{tabular}{|l|c|c|}
\hline Samples and questionnaires & $\begin{array}{c}\text { Total number } \\
\text { collected }\end{array}$ & $\begin{array}{c}\text { Numbers (\%) } \\
\text { actually processed }\end{array}$ \\
\hline Urine specimens from pupils & 1,342 & $1,283(95.6 \%)$ \\
\hline Salt samples collected from households & 902 & $875(97.0 \%)$ \\
\hline Salt samples collected from traders & 365 & $365(100 \%)$ \\
\hline Questionnaires administered on households & 1,134 & $1,134(100 \%)$ \\
\hline Questionnaires administered on traders & 339 & $339(100 \%)$ \\
\hline Questionnaires administered on teachers & 75 & $75(100 \%)$ \\
\hline
\end{tabular}

Table 2: Comparison of the Median Urinary Iodine Concentrations (MUIC) and iodine status of school children in Zambia in 1993, 2002 and 2011

\begin{tabular}{|c|c|c|c|c|c|}
\hline \multirow[t]{2}{*}{ Iodine Status } & \multirow[t]{2}{*}{$(\operatorname{MUIC}(\mu \mathrm{g} / \mathrm{L})$} & \multirow[t]{2}{*}{ Iodine Intake } & \multicolumn{3}{|c|}{$\begin{array}{c}\text { Proportion (\%) of } \\
\text { Children }\end{array}$} \\
\hline & & & 1993 & 2002 & 2011 \\
\hline $\begin{array}{l}\text { Severe iodine } \\
\text { deficiency }\end{array}$ & Below 20 & Insufficiency & 8 & 0 & 1.5 \\
\hline $\begin{array}{l}\text { Moderate iodine } \\
\text { deficiency }\end{array}$ & $20-49$ & Insufficiency & 44 & 0 & 3 \\
\hline Mild iodine deficiency & $50-99$ & Insufficiency & 20 & 4 & 9.6 \\
\hline $\begin{array}{l}\text { Adequate iodine } \\
\text { nutrition }\end{array}$ & $100-199$ & Adequate & 28 & 20 & 24.9 \\
\hline Above requirements & $200-299$ & Above requirements & - & 48 & 21.7 \\
\hline Excessive intake & 300 and above & Excessive & - & 28 & 39.4 \\
\hline Total & & & 100 & 100 & 100 \\
\hline
\end{tabular}

$(-)=$ no data in that category

$\mu \mathrm{g} / \mathrm{L}=$ microgram per litre 


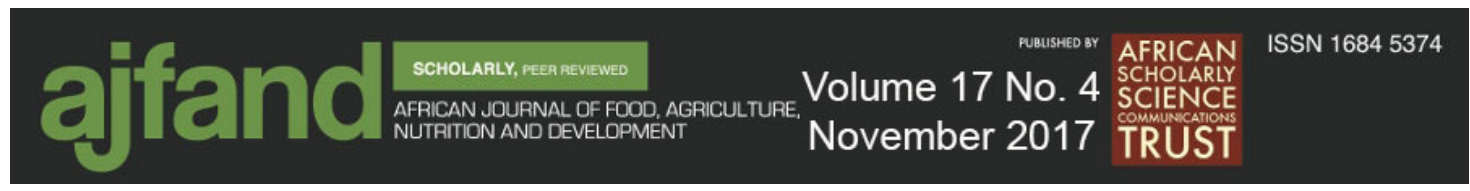

Table 3: Percent of households (coverage) in Zambia with iodized salt in 1993, 2002 and 2011

\begin{tabular}{|l|c|c|c|c|}
\hline Salt iodization & Iodine content in & \multicolumn{3}{|c|}{ Proportion (\%) of households } \\
\cline { 3 - 5 } & salt $\mathbf{( p p m )}$ & $\mathbf{1 9 9 3}$ & $\mathbf{2 0 0 2}$ & $\mathbf{2 0 1 1}$ \\
\hline Insufficient level & $<15$ & - & 6.5 & 20.2 \\
\hline Adequate level & $15-40$ & - & 28.5 & 53.3 \\
\hline Above recommended level & $>40$ & - & 64 & 26.5 \\
\hline Total & & & $\mathbf{1 0 0}$ & $\mathbf{1 0 0}$ \\
\hline
\end{tabular}

$(-)=$ no data in that category

$\mathrm{ppm}=$ parts per million $(\mathrm{mg} / \mathrm{kg})$

Table 4: Sustainable indicators for control and elimination of iodine deficiency in Zambia in 1993, 2002 and 2011

\begin{tabular}{|l|c|c|c|c|}
\hline Sustainable Indicators & $\mathbf{1 9 9 3}$ & $\mathbf{2 0 0 2}$ & $\mathbf{2 0 1 1}$ & Target \\
\hline Children with UIC below $100 \mu \mathrm{g} / \mathrm{L}$ & $72 \%$ & $4 \%$ & $14.10 \%$ & $<50 \%$ \\
\hline Children with UIC below $50 \mu \mathrm{g} / \mathrm{L}$ & $52 \%$ & $0 \%$ & $4.50 \%$ & $<20 \%$ \\
\hline $\begin{array}{l}\text { Households with salt iodine content between } \\
15-40 \text { ppm }\end{array}$ & - & $20 \%$ & $53.30 \%$ & $>90 \%$ \\
\hline Households with salt iodine content $\geq 15 \mathrm{ppm}$ & & $92.5 \%$ & $79.8 \%$ & $>90 \%$ \\
\hline
\end{tabular}

$(-)=$ no data in that category

$\mu \mathrm{g} / \mathrm{L}=$ microgram per litre

ppm $=$ parts per million $(\mathrm{mg} / \mathrm{kg})$

Table 5: Knowledge of Iodine Deficiency among households in Zambia in 2011 (current study)

\begin{tabular}{|l|c|}
\hline Type of knowledge & *Proportion of households \\
\hline Knowledge of at least one type of IDD & $46.9 \%$ \\
\hline Knowledge of causes of goitre & $38.7 \%$ \\
\hline Knowledge of treatment of goitre & $71.0 \%$ \\
\hline Knowledge of prevention of goitre & $34.9 \%$ \\
\hline
\end{tabular}

*Values are cumulative, thus they do not add up to $100 \%$

IDD = Iodine deficiency disorders 


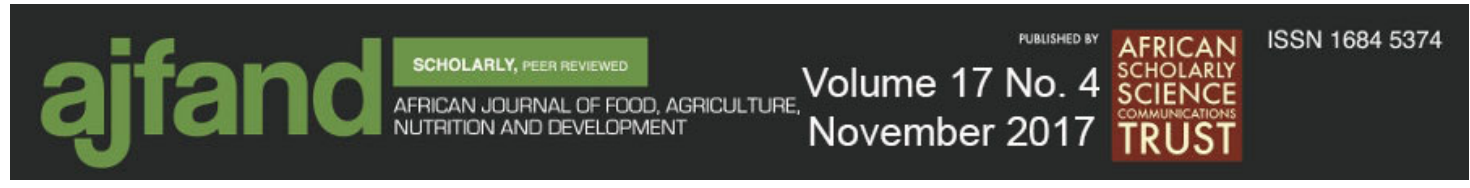

\section{REFERENCES}

1. Delange F The disorders induced by iodine deficiency. Thyroid 1994; 4:107-28.

2. Dumont JE, Ermans AM, Maenhaut F, Coopee F and JB Stanbury Large goiter as a maladaption to iodine deficiency. Clinical Endocrinology, 1995; 43:110 .

3. Hetzel BS Iodine deficiency disorders (IDD) and their eradication. Lancet 1983; 2:1126-1129.

4. Stanbury JB The Damaged Brain of Iodine Deficiency. New York, Cognizant Communication, 1994.

5. Delange F Iodine deficiency as a cause of brain damage. Postgraduate Medical Journal 2001; 77:217-220.

6. Boyages SC Primary pediatric hypothyroidism and endemic cretinism. Current Therapy in Endocrinology and Metabolism 1994; 5:94-8.

7. Bleichrodt $\mathbf{N}$ and MP Born A meta-analysis of research on iodine and its relationship to cognitive development. In: Stanbury JB (ed.). The Damaged Brain of Iodine Deficiency. New York, Cognizant Communication, 1994:195-200.

8. WHO. Elimination of iodine deficiency disorders in South-East Asia. SEA/NUT/138. New Delhi: WHO, 1997.

9. Wynn M and AW Ma Human reproductive and iodine deficiency: Is it a problem in UK? J Nutr Environ Med 1998; 8: 53-64.

10. Bauch K, Meng W, Urlich FE, Grosse E, Kempe R, Schoenemann F, Sterzrl G, Seitz W, Mockel G and A Weber Thyroid status during pregnancy and post partum in regions of iodine deficiency and endemic goitre. Endocrinol Exp 1986; 20:67-77.

11. Herzmann $\mathbf{C}$ and JK Torrens Maternal thyroid deficiency during pregnancy and subsequent neuropsychological development of the child. N. Engl J Med 1999; 341:2015.

12. Tajtakova M, Capova J, Sebokova E and J Petrovicova Thyroid volume, urinary and milk iodine in mothers after delivery and their newborns in iodinereplete country. Endocr regul 1999; 33:9-15.

13. WHO/ UNICEF/ ICCIDD. Assessment of Iodine Deficiency Disorders and Monitoring their Elimination. A guide for programme managers, 2nd ed. World Health Organization. Geneva, Switzerland. 2007. 
14. Delange $\mathbf{F}$, de Benoist $\mathbf{B}$ and $\mathbf{H}$ Burgi Determining median urinary iodine concentration that indicates adequate iodine intake at population level. Bull World Health Organ. 2002; 80: 633-636.

15. Sullivan KM, May S and G Maberly Urinary iodine assessment: A manual on survey and laboratory methods, 2nd ed. UNICEF, PAMM. Atlanta Georgia, USA. 2000.

16. Lumbwe CM, Chowa V, Maonde $\mathbf{N}$, Nyirongo $\mathbf{W}$ and $\mathbf{R}$ Gutekunst Iodine Deficiency Disorders in Zambia. Technical Report. Prepared for National Food and Nutrition Commission. Lusaka, Zambia. 1995.

17. Lumbwe CM, Siamusantu W, Habulembe R, Mwanza M, Nyirongo W and J Campbell Iodine Deficiency disorders (IDD) Impact Survey. Volume 1: IDD indicators. Technical Report. Prepared for National Food and Nutrition Commission of Zambia with support of UNICEF. Lusaka, Zambia. 2003.

18. Besa EM and R Habulembe-Mugode Local salt iodisation activities in Kasempa and Kaputa districts of Zambia. Technical Report. Prepared for the National Food and Nutrition Commission of Zambia with funding from UNICEF. Lusaka, Zambia 2001.

19. Masi C Zambia zeroes in on IDD elimination. IDD Newsletter. 2012.

20. Dunn JT, Critchfield HE, Gutekunst R and AD Dunn Two simple methods for measuring iodine in urine. Thyroid 1993; 3: 119-23.

21. Dunn JT, Myers HE and AD Dunn Simple method for assessing urinary iodine, including preliminary description of a new rapid technique ("Fast B"). Exp Clin Endocrinol Diabetes. 1998; 106(suppl 3): 1005-1007.

22. Guamuch M, Makhumula P and D Omar Manual of laboratory methods for fortified foods. Part I (Determination of Iodine in SALT). East Central and Southern Africa Health Community. Arusha, Tanzania. 2007.

23. Utiger RD Iodine nutrition-more is better. $N$ Engl J Med. 2006; 354:28192821. 